\title{
Considerations Regarding The Quality Of Rehabilitation And Physical Medicine Services From Patients Perspective
}

${ }^{1}$ Balneal and Rehabilitation Sanatorium Techirghiol

${ }^{2}$ Carol Davila University of Medicine and Pharmacy, Bucharest

${ }^{3}$ University "Ovidius" of Constanta, Faculty of Medicine, Constanţa

${ }^{4}$ Rehabilitation Hospital, Eforie Nord

\begin{abstract}
The research study aims to assess the quality of physical medicine and rehabilitation (MFR) services offered to the population by specialized sanatoriums and hospitals in Dobrogea, in order to identify some appropriate measures to improve the quality of such services.

The target group (593 respondents) consisted of 6 independent batches, different in number, selected from 6 medical units. The patients responded to a specific questionnaire regarding the quality of MFR services and the collected data were analyzed statistically.

According to the patients' answers, the medical staff meets their expectations in terms of the information provided at the time of admission, promptitude, kindness, availability, which reflects just one segment of the quality of medical rehabilitation services.

As regards the entity recommending the medical rehabilitation physician, of the total answers, the lowest ratio in the study is held by the answer "family doctor / another doctor". It thus highlights the poor knowledge of family doctors or other doctors on the therapy benefits specific to medical rehabilitation and therefore the access to such services is not facilitated, a disservice to the patients' life quality. There is a dependence relation between the level of education and the reason of admission. We see that is not prevention taking the
\end{abstract}

\section{Carmen Oprea}

Dr. Victor Climescu St. no. 34-40, Techirghiol, Constanta, Romania

email : carmen oprea cta@yahoo.com

phone: +40241481711 first position, but the pain, which reflects a deficient education for health in all social levels

Assessing the patient's satisfaction regarding the mobility facilities in the sanatorium / hospital a percentage of $6.6 \%$ patient responded that they are not satisfied. It results that all the 6 partner institutions in the study must evolve to provide decent conditions ensuring the mobility independence to the patients

Keywords: patients, satisfaction, rehabilitation, health, quality

\section{Introduction}

The concept of health service quality is highly complex, its definition being different from one author to another. Thus, according to researcher Avedis Donabedian, a pioneer in the field, a quality health service is the service aiming to maximize the patients' welfare, considering the benefits / risks ratio in each stage of the medical care process [1]. The World Health Organization defines it as the ability to guarantee each patient a set of diagnosis and therapeutic procedures ensuring the best result in terms of health, according to the current status of medical progress, against the best cost for the same result, the lowest iatrogenic risk, for the full satisfaction in terms of procedure, results, human contact within the health system [2]. It must be noted that a quality health service does 
not guarantee a positive result, but only increases the probability of achieving such a result [3].

At the same time, Donabedian identifies four levels for the approach of health service quality [4]: health services provided by medical staff; facilities and equipment (the quality of health services represented by the facilities used within the health system, which must ensure a certain comfort to the patients, be pleasant, clean and observe privacy and confidentiality); the care by the patient and the health services received by the community. Therefore, the quality of health services is a multi-dimensional concept, embedding opinions of several players, amongst which the patient's [5].

The health services made available to the patients also include medical and physical rehabilitation services (MFR) intended to assist "individuals facing or prone to disabilities in order to reach and maintain the best functionality in the interaction with their environments" [6].

The purpose of this research study is to assess the quality of MFR services offered to the population by specialised sanatoriums and hospitals in Dobrogea, in order to identify some appropriate measures to improve the quality of such services. We pursued objectives such as an analysis of the feedback from patients regarding the quality of MFR services and establishing the real measures required to improve the medical activity in relation to the patients' expectations and needs.

\section{RESEARCH MATERIAL AND METHOD}

The research method used is represented by the basic prospective investigation on grounds of specific questionnaires [7] regarding the quality of MFR services, applied to patients in six MFR sanatoriums / hospitals in Dobrogea, both private - Balneal Complex Vraja Marii - Eforie Sud (CVM), Ovidius Clinical Hospital (OCH), and public - Techirghiol Balneal and Recovery Sanatorium (SBRT), Recovery Hospital, Eforie Nord Physical Medicine and Balneology
(SGRAND), Balneal Sanatorium Mangalia (SBM), Tulcea Emergency County Hospital (SJUT).

The study was carried out in 2015 and was applied to 593 respondents, observing the study protocol. The target group consisted of 6 independent batches, different in number, selected from each medical unit. The informed consent was created starting from the generally accepted model, observing the legal regulations in the field of medical research in force in Romania and the European Union [8] and adapted to the non-therapeutic research involving human subjects.

The patient specific questionnaire was prepared on grounds of six quality criteria (personal data; admission to the sanatorium / hospital; physician; nurses; kinetotherapists; treatment, environment and facility), each with specific questions. The answers were collected observing the data confidentiality [9], after the patients completing the questionnaire. The data base was prepared and subject to statistical analysis using the processing software IBM SPSS Statistics 20. The procedures used were: Descriptive statistics, Figures, Non-parameter statistical tests (test $\chi^{2}$ regarding the association, the connection between two category variables), Additional procedures for the comparison of multiple proportions [10].

\section{RESULTS AND DISEUSSIONS}

Looking at the results of the research study applied to the patients as a whole, we can see a representation of all demographic and social categories aimed by the questionnaire (of the total target group, $64.1 \%$ women, main age group over 60 $(45.5 \%)$, followed by the age group of $40-60(44.2 \%)$, $47.7 \%$ of the respondents are graduates of higher education, followed by graduates of elementary education on a percentage of $18 \%$, and $86 \%$ of the respondents from urban areas). This helps outlining of a real image on the current situation in the field of medical rehabilitation services in Dobrogea.

According to the patients' answers, the 
medical staff meets their expectations in terms of the information provided at the time of admission $(89.2 \%)$, observance of privacy during the medical examination $(100 \%)$, consistency of answers received to a specific question (84.7\%), promptitude, kindness, availability $(100 \%)$ reflecting just one segment of the quality of medical rehabilitation services. On the other hand, analysing the questions regarding other aspects of health services available in the medical units participating to the study we see the following:

As regards the entity recommending the medical rehabilitation physician, of the total answers, the highest ratio is held by "I am a long term patient" (Figure 1), as the answer provided most often in case of public sanatoriums and hospitals. This is probably due to the fact that SBRT and SGRAND are sanatoriums with therapeutic tradition as compared CVM, forinstance, a new hospital promoted, according to the answers, by "A patient / acquaintance". In both cases, we can conclude that a significant percentage of the patients see the therapeutic results and medical services accessed in positive manner, considering they return to the treatment unit or recommend such to acquaintances.

The lowest ratio in the study $(15.9 \%)$ is held by the answer "Family doctor/another doctor" (Figure 1). The poor knowledge of family doctors or other doctors on the therapy benefits specific to medical rehabilitation is therefore outlined and thus the access to such services is not facilitated, a disservice to the patients' life quality. At the same time, it was seen that there are significant differences between the answers $\left(\left|\mathrm{p}_{\mathrm{i}}-\mathrm{p}_{\mathrm{j}}\right|<\mathrm{r}_{\mathrm{i}, \mathrm{cr}}\right)$ concerning hospitals and sanatoriums: SGRAND-CVM, SBRT-SJUT, SBRT-SGRAND, SJUT-OCH, SJUT-CVM. This can be due to the different contracts with the National Health Insurance System on one hand, and on the other hand family doctors / other doctors are better informed in terms of hospitals than sanatoriums.

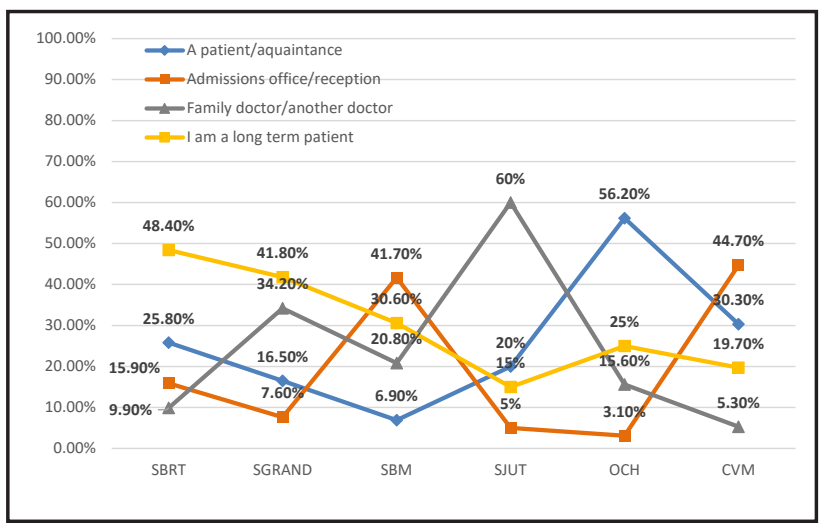

Figure 1 Entity recommending the medical rehabilitation physician

The level of education of the patients gives us information on the social categories interested in maintaining or improving the health condition. There is some dependence $(p=0.007<\alpha=0.05$.) between the level of education (higher / elementary education) significantly adding to the value of $\chi^{2}$ calc $(|\mathrm{Rs}|=$ 2.1 ) and the reason of admission (pain). We see that is not prevention taking the first position, reflecting a deficient education for health in all social levels (Table I).

\begin{tabular}{|llll|} 
& Value & df & $\begin{array}{l}\text { Asymp. Sig. } \\
(2-\text {-sided })(p)\end{array}$ \\
\hline $\begin{array}{l}\text { Pearson Chi- } \\
\text { Square }\left(\chi^{2} \text { calc }\right.\end{array}$ & $17,788^{a}$ & 6 & 0,007 \\
\hline Likelihood Ratio & 17,957 & 6 & 0,006 \\
\hline $\begin{array}{l}\text { Linear-by-Linear } \\
\text { Association }\end{array}$ & 14,042 & 1 & 0 \\
\hline N of Valid Cases & 593 & & \\
\hline
\end{tabular}

When referring to procurement of aid devices during treatment and advice concerning their use, upon analyzing Table II, we observe that of the $12.5 \%$ patients with permanent or temporary disabilities, the hospital failed to provide the necessary aid devices during treatment for only an infinitesimal percentage of $0.2 \%$. At the same time, of the total target group, $2 \%$ claim the lack of advice on the correct use of such devices (Figure 2). This demonstrates the allocation by the medical staff of sufficient time to disabled persons as compared to the actually necessary time. 
Table I. Dependency relation between patients'level of education and reason for accessing medical rehabilitation

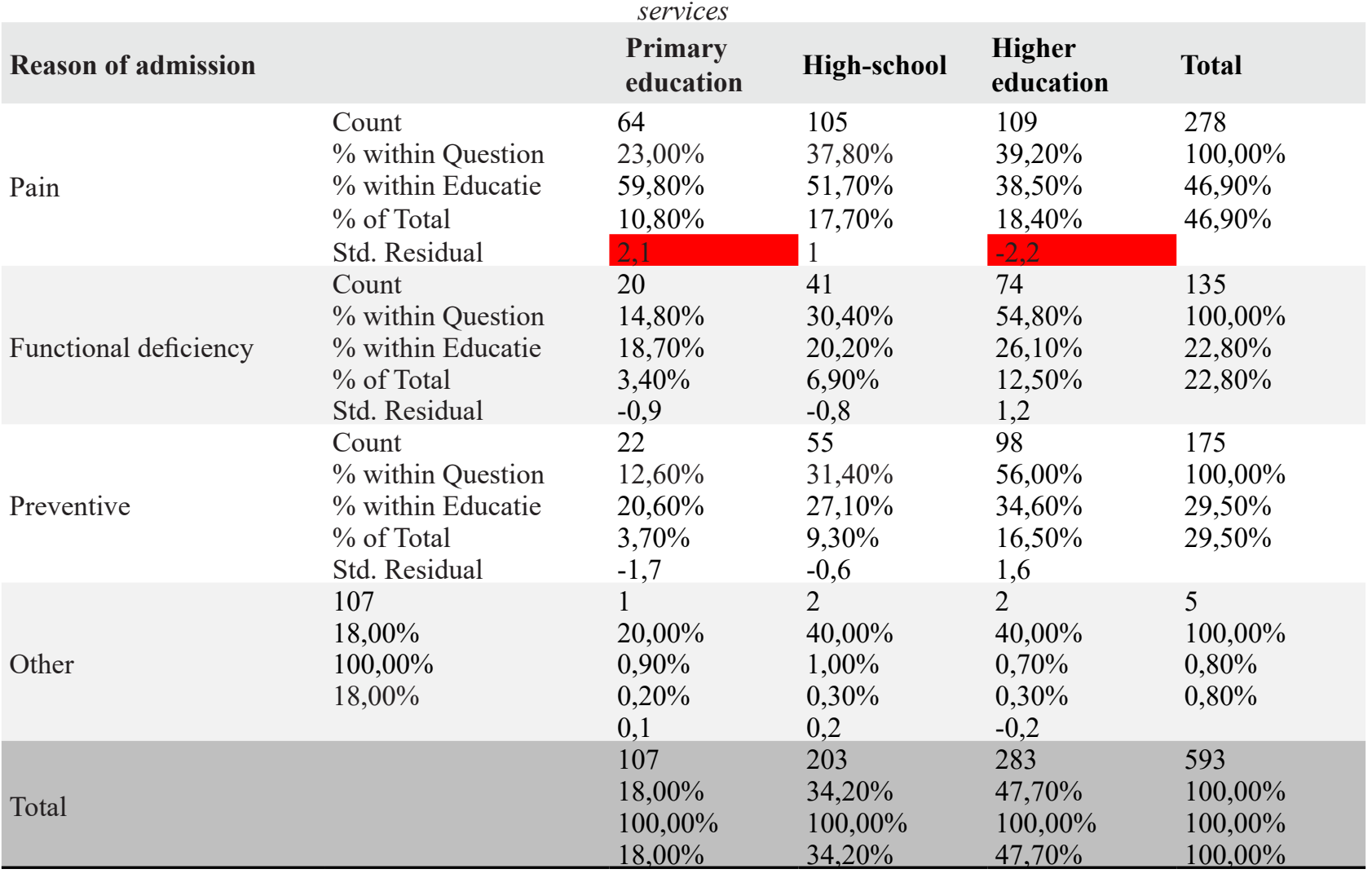

Table II. Procurement of aid devices during treatment

\begin{tabular}{|c|c|c|c|c|c|}
\hline \multirow[t]{2}{*}{ Location } & \multicolumn{4}{|c|}{ Procurement of aid devices during treatment } & \multirow[t]{2}{*}{ Total } \\
\hline & $\begin{array}{l}\text { Sanatorium/ } \\
\text { hospital }\end{array}$ & $\begin{array}{l}\text { Sanatorium/ } \\
\text { hospital\& myself }\end{array}$ & $\begin{array}{l}\text { The hospital did } \\
\text { not provide them }\end{array}$ & I did not need & \\
\hline \multirow[t]{2}{*}{ SBRT } & 24 & 12 & 0 & 278 & 314 \\
\hline & $7.6 \%$ & $3.8 \%$ & $0.0 \%$ & $88.5 \%$ & $100.0 \%$ \\
\hline \multirow[t]{2}{*}{ SGRAND } & 5 & 3 & 0 & 71 & 79 \\
\hline & $6.3 \%$ & $3.8 \%$ & $0.0 \%$ & $89.9 \%$ & $100.0 \%$ \\
\hline \multirow[t]{2}{*}{ SBM } & 3 & 1 & 0 & 68 & 72 \\
\hline & $4.2 \%$ & $1.4 \%$ & $0.0 \%$ & $94.4 \%$ & $100.0 \%$ \\
\hline \multirow[t]{2}{*}{ SJUT } & 0 & 1 & 0 & 19 & 20 \\
\hline & $0.0 \%$ & $5.0 \%$ & $0.0 \%$ & $95.0 \%$ & $100.0 \%$ \\
\hline \multirow[t]{2}{*}{$\mathrm{OCH}$} & 9 & 3 & 1 & 19 & 32 \\
\hline & $28.1 \%$ & $9.4 \%$ & $3.1 \%$ & $59.4 \%$ & $100.0 \%$ \\
\hline \multirow[t]{2}{*}{ CVM } & 12 & 0 & 0 & 64 & 76 \\
\hline & $15.8 \%$ & $0.0 \%$ & $0.0 \%$ & $84.2 \%$ & $100.0 \%$ \\
\hline \multirow[t]{2}{*}{ Total } & 53 & 20 & 1 & 519 & 593 \\
\hline & $8.9 \%$ & $3.4 \%$ & $0.2 \%$ & $87.5 \%$ & $100.0 \%$ \\
\hline
\end{tabular}




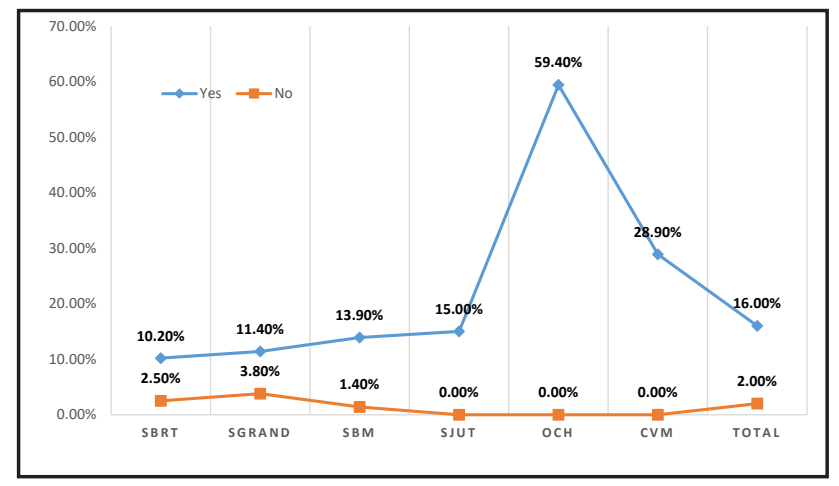

Figure 2 Advising patients on the use of aid devices

Assessing the patient's satisfaction regarding the mobility facilities in the sanatorium / hospital: although most persons interviewed (93.4\%) said they were satisfied with the mobility facilities in the medical treatment institutions, we believe the 6.6\% percentage of negative answers (Table III) must alarm us, given that it should be $0 \%$. It results that all the 6 partner institutions in the study must evolve to provide decent conditions ensuring the mobility independence to the patients $[11,12]$.

Table III Patient's satisfaction regarding the mobility facilities in the sanatorium/ hospital

\begin{tabular}{|lccr|}
\hline \multirow{2}{*}{ Location } & \multicolumn{3}{c}{$\begin{array}{c}\text { Patient's satisfaction } \\
\text { regarding the mobility } \\
\text { facilities }\end{array}$} \\
& Yes & No & \\
\hline SBRT & 291 & 23 & 314 \\
\cline { 2 - 4 } & $92.7 \%$ & $7.3 \%$ & $100.0 \%$ \\
\hline SGRAND & 75 & 4 & 79 \\
\cline { 2 - 4 } & $94.9 \%$ & $5.1 \%$ & $100.0 \%$ \\
\hline SBM & 65 & 7 & 72 \\
\cline { 2 - 4 } & $90.3 \%$ & $9.7 \%$ & $100.0 \%$ \\
\hline SJUT & 17 & 3 & 20 \\
\cline { 2 - 4 } & $85.0 \%$ & $15.0 \%$ & $100.0 \%$ \\
\hline OCH & 31 & 1 & 32 \\
& $96.9 \%$ & $3.1 \%$ & $100.0 \%$ \\
\hline CVM & 75 & 1 & 76 \\
\cline { 2 - 4 } & $98.7 \%$ & $1.3 \%$ & $100.0 \%$ \\
\hline Total & 554 & 39 & 593 \\
& $93.4 \%$ & $6.6 \%$ & $100.0 \%$ \\
\hline
\end{tabular}

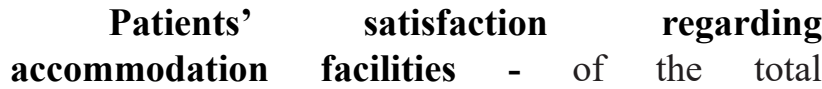
respondents, $84.7 \%$ said they were satisfied with the accommodation facilities (support, shower seat / rest room / toilet) and the remaining $15.3 \%$ said the accommodation facilities were not according to their needs. For "Yes" and "No" answers, there are significant differences $\left(\left|\mathrm{p}_{\mathrm{i}}-\mathrm{p}_{\mathrm{j}}\right|<\mathrm{r}_{\mathrm{i}, \mathrm{c}, \mathrm{r}}\right)$ between SBRT OCH, SGRAND - OCH, SBM-OCH, SBM - CVM, SUJT - OCH. We can therefore see a high difference between public and private hospitals (Figure 3). According to the target group answers, the public medical units fail to fully meet the patients' needs in terms of accommodation, while private medical units are appreciated for existing endowments. The difference is probably caused by the allocation of insufficient funds from the state budget, local budget or internal funds to equip the public institutions in question according to the quality standards applied at national and European level.

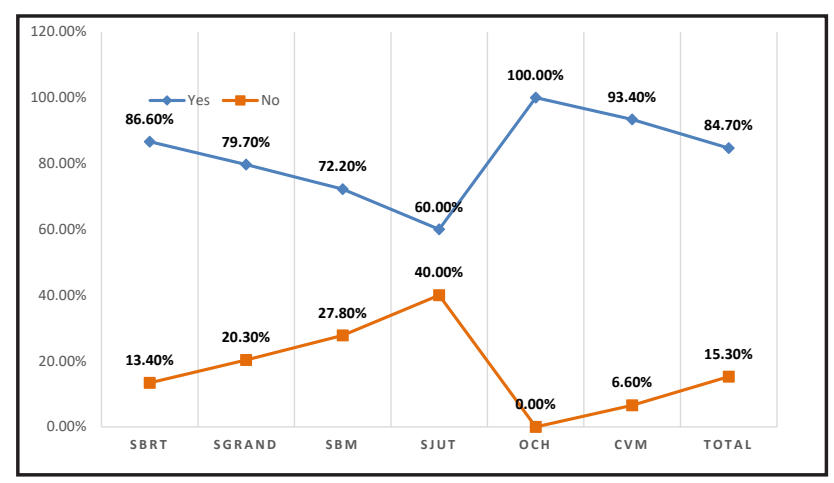

Figure 3 Patients'satisfaction regarding accommodation facilities

The patients questioned about the need of leisure areas / commercial services and patient personal care, answered in a percentage of $89.4 \%$, $54.6 \%$ respectively (Table IV) that they needed the setting up of a leisure area and the organization of some entertainment activities, respectively the existence of some commercial and personal care services in the premises or near the medical units. We observe that many patients consider necessary the setting up of such spaces. 
Table IV Patients'opinion about the necessity of setting up leisure and personal care areas

\begin{tabular}{|c|c|c|c|c|c|}
\hline \multirow[t]{2}{*}{ Location } & \multicolumn{2}{|c|}{ Setting up a leisure area? } & \multicolumn{2}{|c|}{ Setting up a personal care area? } & \multirow[t]{2}{*}{ Total } \\
\hline & Yes & No & Yes & No & \\
\hline \multirow[t]{2}{*}{ SBRT } & 291 & 23 & 194 & 120 & 314 \\
\hline & $92.7 \%$ & $7.3 \%$ & $61.8 \%$ & $38.2 \%$ & $100.0 \%$ \\
\hline \multirow[t]{2}{*}{ SGRAND } & 74 & 5 & 33 & 46 & 79 \\
\hline & $93.7 \%$ & $6.3 \%$ & $41.8 \%$ & $58.2 \%$ & $100.0 \%$ \\
\hline \multirow[t]{2}{*}{ SBM } & 69 & 3 & 33 & 39 & 72 \\
\hline & $95.8 \%$ & $4.2 \%$ & $45.8 \%$ & $54.2 \%$ & $100.0 \%$ \\
\hline \multirow[t]{2}{*}{ SJUT } & 13 & 7 & 9 & 11 & 20 \\
\hline & $65.0 \%$ & $35.0 \%$ & $45.0 \%$ & $55.0 \%$ & $100.0 \%$ \\
\hline \multirow[t]{2}{*}{$\mathrm{OCH}$} & 26 & 6 & 13 & 19 & 32 \\
\hline & $81.2 \%$ & $18.8 \%$ & $40.6 \%$ & $59.4 \%$ & $100.0 \%$ \\
\hline \multirow[t]{2}{*}{ CVM } & 57 & 19 & 42 & 34 & 76 \\
\hline & $75.0 \%$ & $25.0 \%$ & $55.3 \%$ & $44.7 \%$ & $100.0 \%$ \\
\hline \multirow[t]{2}{*}{ Total } & 530 & 63 & 324 & 269 & 593 \\
\hline & $89.4 \%$ & $10.6 \%$ & $54.6 \%$ & $45.4 \%$ & $100.0 \%$ \\
\hline
\end{tabular}

\section{CONGLUSIONS}

Considering the specifics of medical rehabilitation services accessed by an increasing number of disabled persons (13), it is necessary to improve the services provided to them (14), (15), as well as to other patients. Thus, in order to increase the patient's satisfaction and, implicitly, the quality of existing services in the physical medicine and medical rehabilitation, the following improvements result as priorities:

A. Parking areas for patients provided with the surface of $3.75 \mathrm{~m} 2 /$ bed and ramp for disabled persons or stretcher.

B. Considering the current geo-political background, in order to ensure the security of patients and of the institution, security staff should be provided at the medical unit entrance and visitor logged into a register. For disabled persons, there should be a wheelchair and a medical staff calling system.

C. To prevent infections associated with medical care, visitors should wear specific equipment (disposable shoes, used equipment disposal container).

D. Corridors connecting accommodation area, meal area and therapy area should be converted and should benefit of a $240 \mathrm{C}$ thermal comfort. Also, corridors should be provided with ramps for disabled persons in the stair area, with handrails (support) both on the right side and the left side, with the minimum distance of $1 \mathrm{~m}$ in between.

E. Elevators should operate $24 \mathrm{~h} /$ day and, at the level of each accommodation area, there should be at least 1 elevator with the surface of $3 \mathrm{~m} 2$ (for the stretcher).

F. The room should have the useful surface of at least $10 \mathrm{~m} 2 /$ bed and a volume of at least $20 \mathrm{~m} 3$ air/bed. The room should contain up to maximum 3 beds, the distance between 2 beds and the door width (room, rest room, balcony) exceeding $0.90 \mathrm{~m}(0.90$ $\mathrm{m}$ being the width of a wheelchair). As regards the room facilities, the following should be provided: antibacterial and adherent pavement with rounded joints, overhead lighting, right side and left side handrails, beds with the sizes of $\mathrm{L}=2 \mathrm{~m}, \mathrm{l}=0.90$, $\mathrm{h}$ $=0.60 \mathrm{~m}$. At the same time, a modular bed should be provided for $1 / 3$ of the total number of beds, clamping 
/ hanging systems for $10 \%$ of the total number of beds and fold night stands for $1 / 3$ of the total number of beds. The rest room in the room can be standard with a minimum surface of $3.5 \mathrm{~m} 2$ (with standard fittings including shower seat for old persons) and with the possibility to adapt it to disabled persons. Thus, it should have the minimum surface of $4.5 \mathrm{~m} 2$ and contain: 1 shower cabin accessible to the disabled person (no thresholds) and to the nurse, shower seat for disabled persons, support, mirror, sink, toilet seat located to be accessible to the disabled patient.

G. The treatment base, in our opinion, should be connected to accommodation areas by means of corridors and benefit of a $240 \mathrm{C}$ thermal comfort all year round. Therapy beds should have the sizes: $\mathrm{L}=$ $2 \mathrm{~m}, \mathrm{l}=0.90 \mathrm{~m}, \mathrm{~h}=0.60 \mathrm{~m}$, and the bath tubs should be fitted with adherent bottom and supports for disabled persons. As regards the number of orthopaedic equipment (crutches, walking frame, etc.), it should be reported to the number of specific pathology cases in the previous year.

H. The lunch room should be provided with natural ventilation, climate ventilation and ramps for disabled persons. The patient's feeding in the bed shall not entail the mandatory presence of the food pantry and annexes at the level of each sanatorium story, if the prevention norms regarding nosocomial infections IAAM are observed.

I. The treatment plan prepared by an interdisciplinary team entails the MFR hospital / sanatorium be fitted with: occupational therapy cabinet (ergo therapy), cardiology cabinet. The electronic medical records must include a field / box to check disabled / immobilised persons, useful in case of emergencies / disasters / fire. At the same time, to improve the recovery process, the following are necessary: a library containing at least 2 books / bed; a covered area for leisure and social activities for patients, of at least $0.5 \mathrm{~m} 2 / \mathrm{bed}$; green area (therapeutic park) with the minimum surface of 3.5 $\mathrm{m} 2$ /bed; hair saloon, spam manicure, commercial area with various items (excluding alcoholic drinks and tobacco products) given that it is a known fact that patients attending themselves and giving time to their physical looks recovers faster in psychological and physical terms, thus enhancing the positive results of the medical rehabilitation treatment. We must note the need to align the laws and the patients' needs and expectations to that end.

J. To solve the problems faced by the patient (immobilised or depending on another person) and their family, we need to size the auxiliary staff according to the cases and the patient's care needs. The service can, according to law, be a source of revenues for the medical institution. Upon the interview investigation (briefing interview) the following ratio is required to improve the medical act at the sanatorium level: 1 nurse for each 5 disabled patients, in wheelchairs and 1 nurse for each 20 disabled patients moving independently / aided.

\section{Acknowledgements}

The authors would like to thank the six medical institutions which have contributed to the progress of the research.

No Conflicts of interests to declare.

\section{References}

1. Donabedian, A. (1966). Evaluating the quality of medical care. Milbank Mem Fund Q. 44(3), Suppl:166-206.

2. Roemer, M.I. \& Montoya-Aguilar, C. (1988). Quality assessment and assurance in primary health care. WHO Offset Publ(105), 1-78.

3. Committee to Design a Strategy for Quality Review and Assurance in Medicare - Institute of Medicine. (1990). Medicare: A Strategy for Quality Assurance. National Academy Press. Washington

4. Donabedian, A. (1980). Explorations in quality assessment and monitoring. The Definition of Quality and Approaches to Its Assessment: 
Health Administration Press.

5. Armean P. (2004). Health management. Fundamental notions of public health. Ed. C.N.I. Coresi, Bucharest

6. World Health Organization (2012). World Report on Disability. Bucharest

7. Sigitas G. (2006). Patients'perceived satisfaction with hospital services. Nordic School of Public Health. ISSN 1104-5701

8. Directive 95/46/EC of the European Parliament and of the Council of October $24^{\text {th }} 1995$ on the protection of individuals with regard to the processing of personal data and on the free movement of such data

9. Law no. 677/2001 on the protection of individuals with regard to the processing of personal data and the free circulation of these data, published in Monitorul Oficial no. 790 of December $12^{\text {th }}$ 2001

10. Lupu, G., Petcu, L.C., Lupu, E.C. (2006). Applied Mathematics and Biostatistics, Ed. Virom, Constanţa
11. The Convention on the Rights of Persons with Disabilities of the United Nations General Assembly, adopted on December $13^{\text {th }} 2006$ and opened for signature on 30 March 2007. Article 26. New York

12. European Parliament Resolution from July $7^{\text {th }}$ 2016 on the implementation of the UN Convention on the Rights of Persons with Disabilities, with special regard to the Concluding Observations of the UN CRPD Committee (2015/2258(INI). Articles 38 and 47

13. Ministry of Labor, Family and Social Protection - National Authority for People with Disabilities. Statistic Bulletin, Third trimester (September $30^{\text {th }}$ 2016). Bucharest

14. Law no. $448 / 2006$ on the protection and promotion of the rights of persons with disabilities, republished in Monitorul Oficial no. 1 of January $3^{\text {rd }} 2008$

15. National Health Strategy 2014-2020 approved by Government Decision no. 1028 of 18 November 2014 and published in Monitorul Oficial no. 891 of December $8^{\text {th }} 2014$ 